\title{
Estimation of Soil Water Retention Curve Using Fractal Dimension
}

\author{
${ }^{1}$ SEYEDEH, ZM; ${ }^{* 1}$ EBRAHIM, P; ${ }^{2}$ FARIBORZ, A; ${ }^{3}$ HOSSEIN, B \\ ${ }^{* 1}$ Department of Soil Science, ${ }^{3}$ Department of Water Sciences and Engineering, Science and Research Branch, Islamic Azad University,
Tehran, Iran \\ ${ }^{2}$ Agricultural Engineering Research Institute, Agricultural Research, Education and Extension Organization, Karaj, Iran
}

\begin{abstract}
The soil water retention curve (SWRC) is a fundamental hydraulic property majorly used to study flow transport in soils and calculate plant-available water. Since, direct measurement of SWRC is time-consuming and expensive, different models have been developed to estimate SWRC. In this study, a fractal-based model was developed to predict SWRC. A wide range of soil textures (130 soil samples) was used to determine the fractal dimension of SWRC ( $D_{\text {SWRC }}$ ). Moreover, the SWRC pedotransfer functions were established based on easily available soil properties such as particle size distribution and bulk density by applying multiple linear regression analysis. The measured $\mathrm{D}_{\text {SWRC }}$ for 110 soil samples was considered for function parameterization and the remaining was used for model validation. The results illustrated that the $\mathrm{D}_{\text {SWRC }}$ linearly correlates with clay and silt contents and soil bulk density $\left(r^{2}=0.909\right)$. The SWRC can, therefore, be easily and concisely estimated by the proposed fractal-based functions.
\end{abstract}

DOI: https://dx.doi.org/10.4314/jasem.v21i7.25

Copyright @ 2017 Seyedeh et al. This is an open access article distributed under the Creative Commons Attribution Non-Commercial License (CC-BY-NC), which permits unrestricted use, distribution, and reproduction in any medium, provided the original work is properly cited.

Received 11 May 2017, received in revised form 12 November 2017, accepted 01 December 2017.

Keywords: Fractal model; Pedotransfer functions; Regression analysis; Soil water retention curve

The increasing concern with groundwater pollution and contamination of soils has stimulated the development of numerous mathematical models of pollutant transport in soils. The most important approaches to model transient water and solute transport in the vadose zone are based on the Richards equation. To solve this equation, the knowledge of the soil hydraulic properties, namely, the soil water retention curve (SWRC) and the unsaturated hydraulic conductivity is required and on the other hand, Measurements of hydraulic properties are expensive, time-consuming and highly variable (Patil and Chore, 2014).

The soil water retention curve (SWRC) is one of the important hydraulic functions in water flow modeling and solute transport in the porous medium. Many theoretical and empirical models for the SWRC have been developed (Brooks and Corey, 1964; van Genuchten, 1980; Russo, 1988). Models parameters are usually estimated by fitting the functions to measured SWRC data. Recently, the pedotransfer functions are used to empirically describe the relationship between the parameters and basic soil data (Scheinost et al., 1997; Schaap et al., 1998; Minasny et al., 1999; Elsenbeer, 2001; Wo"sten et al., 2001). Modern hydrological models require information on hydraulic conductivity and soil-water retention characteristics. All hydraulic properties, the soil-water characteristics, hydraulic conductivity and soil-water diffusivity (SWD) are closely related to the geometry of a porous media (Brooks and Corey,
1966; Burdine, 1953). In recent years, the formulation of fractal geometry has attracted much attention as a powerful tool for describing various complex natural phenomena, in particular, in mechanics and physics of rocks and soils (Turcotte, 1992; Borodich, 1997).

Recent applications of fractal geometry provide a useful tool to bridge the gap between the use of empirical models and physical interpretation of their parameters (Tyler and Wheatcraft, 1990; Rieu and Sposito, 1991a,b; Perrier et al., 1996; Perfect et al., 1998). It has been shown that both the solid and pore phases have affine self-similarity, which can be characterized by different fractals (Gime'nez et al., 1997). Fractals describe hierarchical systems and are suitable to model the heterogeneous soil structure with tortuous pore space (Rieu and Sposito,1991a; $\mathrm{Xu}$ and Sun, 2002). Toledo et al., (1990) modeled the soil-water characteristic curve (SWCC) and unsaturated hydraulic conductivity using fractal geometry and thin-film theory. Tyler and Wheatcraft (1990) derived the unsaturated hydraulic conductivity functions based on the fractal model for the soilwater characteristic curve (SWCC) and the relative conductive models developed by Mualem (1976) and Burdine (1953).

In general, fine-textured soils have higher fractal dimensions, while coarse-textured soils have smaller fractal dimensions (Tyler and Wheatcraft, 1992; Comegna et al., 2000; Huang and Zhan, 2002). 
Fractal dimensions of the solid matrix (that is, soil particle size distribution and soil texture) and the void phase (that is, soil pore size distribution and soil pore surface) can characterize by the fractal nature of soils. Nevertheless, further study is required to quantify the relationship among the fractal dimensions of the soil solid and void phases and the fractal dimension used in the SWRC (Huang and Zhang, 2005). Perfect (2005) used the fractal geometry to simulate porous media structure and revised by Cihan et al., (2007). A sensitivity analysis that was carried out on Tyler and Wheatcraft (1990) model showed that the SWRC fractal dimension ( $\left.\mathrm{D}_{\text {SWRC }}\right)$ is the most sensitive parameter in model, whereas this model is less sensitive to the saturated water content and air entry value (GhanbarianAlavijeh et al., 2008 ). Some other researchers applied the fractal theory to investigate the SWRC and used the fractal dimensions of the SWRC to describe the corresponding SWRC (Wang et al., 2005; Ghanbarian-Alavijeh and Hunt, 2012). However the exponent of soil water retention curve, $\mathrm{D}_{\text {SWRC }}$ is physically meaningful, its direct measurement is difficult in laboratory and also field soil water retention experiments are laborious and time consuming. So estimation of $\mathrm{D}_{\text {SWRC }}$ based on the available data, can be very useful alternative.

As mentioned, Porous media (e.g. soils, rocks, etc.) are heterogeneous systems composed of numerous, different and interacting components and the complex nature of them complicates any prediction of their hydraulic properties (van Damme, 1995). Soil particle size distribution has fractal properties. Hence, fractal model can be used to estimate the soil water retention curve. Thus determining the $\mathrm{D}_{\text {SWRC }}$ from SWRC experimental data, establishing a relationship among $\mathrm{D}_{\text {SWRC }}$ and soil readily available characteristics (i.e. clay, silt and sand contents and bulk density), and finally validating the developed relationship in SWRC estimation were the main objectives of this study.

\section{MATERIALS AND METHODS}

Study area: A set of disturbed and undisturbed soil samples were collected from top $30 \mathrm{~cm}$ soil horizon of Varamin, Iran (from $35^{\circ} 110^{\prime} 46.07^{\prime \prime}$ to $35^{\circ} 02^{\prime}$ $41.65^{\prime \prime}$ east longitudes and from $51^{\circ} 33^{\prime} 49.92^{\prime \prime}$ to $51^{\circ}$ 47' 02.66" north latitudes). The climate of the region is categorized as semi-arid with mean annual temperature and precipitation of $18^{\mathrm{oC}}$ and $150 \mathrm{~mm}$, respectively (Moravvej et al., 2003) and the soil is classified as Xeric Haplocalcid (Moravvej et al., 2003).
Soil sampling and soil properties measurement: The soil samples cover most range of texture classes. Table 1 shows the general characteristics of studied soils. Disturbed samples were air dried, passed through $2 \mathrm{~mm}$ sieve, so, soil texture determined according to the USDA texture classification standards (Hillel, 1998). Undisturbed samples were used to measure bulk density (Blake and Hartge, 1986) and to obtain SWRC. The soil water retention data were measured using the pressure plate apparatus (Model 1500, Soil moisture Equipment, CA) at seven matric potentials $(100,300,1000,3000$, 5000,10000 and $15000 \mathrm{~cm}$ ), , then the SWRC for each soil was determined.

Table 1: Some statistic parameters of soil properties $(n=130)$.

\begin{tabular}{lccc}
\hline \multicolumn{1}{c}{ Soil properties } & Maximum & Minimum & Mean \\
\hline Clay (\%) & 53.96 & 15.68 & 36.81 \\
Silt $(\%)$ & 71.2 & 27.64 & 50.68 \\
Sand $(\%)$ & 26.84 & 7.04 & 12.50 \\
Bulk density $\left(\mathrm{gcm}^{-3}\right)$ & 1.75 & 1.44 & 1.59 \\
\multicolumn{1}{c}{ Lime $(\%)$} & 28 & 7 & 17.35 \\
\hline
\end{tabular}

Method: The fractal model used in this study was the Tyler and Wheatcraft (1990) model that express by Eq. 1 as:

$\boldsymbol{\theta}=\boldsymbol{\theta}_{S}\left(\frac{\Psi}{\Psi_{a}}\right)^{D_{m}-3}$

Where $\psi$, is the capillary tension head $(\mathrm{cm})$ and $\theta$ is the soil water content $\left(\mathrm{cm}^{3} \mathrm{~cm}^{3}\right), \theta_{\mathrm{s}}$, is the saturated soil water content $\left(\mathrm{cm}^{3} \mathrm{~cm}^{3}\right), \psi_{\mathrm{a}}$ is the air entry pressure $(\mathrm{cm}), \mathrm{D}_{\mathrm{m}}$ is the fractal dimension of SWRC.

The measured $\mathrm{D}_{\mathrm{SWRC}}$ for 110 soil samples, used for regression analysis and 20 soil samples was used for model validation. So, 110 soil samples in the regression model were employed to derive the relationship between the fractal dimension of SWRC and other soil physical parameters including clay, silt and sand percent and bulk density. Multiple Linear Regression analysis was done using Sigma Plot software.

Quantitative assessment of model performances: To test the validity of the model in predicting retention curve plot of observed and estimated values, determining factor $\left(\mathrm{R}^{2}\right)$ (at the significant level of $1 \%$ ) and Root Mean Square Error $\left(\mathrm{R}_{\mathrm{MSE}}\right)$ was used.

Model calibration: To calibrate the model, were drawn the moisture content of the initial and final points of measured and estimated soil water retention curves ( 100 and $15000 \mathrm{~cm}$ ), and was used the slope and intercept of the fitted line on the two points for calibration (Ghanbarian-Alavigeh, et al., 2007). 
The estimated soil water retention curves were compared with the measured data, and the difference between the estimated soil water retention curves and the measured data was then quantified by using the Mean Absolute Error (MAE) and Mean Square error (MSE). Linear regression was then performed between measured and estimated water content for all soils and coefficients of determination $\left(\mathrm{R}^{2}\right)$ was determined.

\section{RESULTS AND DISCUSSION}

The SWRC fractal dimension determining with soil moisture curve, ranged between 2.73 to 2.89 for loam and clay soil texture classes. Table 2 shows the

Table 2: Values of maximum, minimum and average soil moisture curve measured fractal dimensions for texture studied $(n=130)$.

\begin{tabular}{lccc}
\hline \multirow{2}{*}{ Texture } & \multicolumn{3}{c}{ Measured fractal dimension } \\
\cline { 2 - 4 } & Max & Min & Mean \\
Silty Loam & & & \\
Clay Loam & 2.764 & 2.733 & 2.748 \\
Silty Clay Loam & 2.787 & 2.781 & 2.784 \\
Silty Clay & 2.817 & 2.790 & 2.800 \\
Clay & 2.882 & 2.788 & 2.836 \\
\hline
\end{tabular}

Based on the results, the relationship among the fractal dimension of SWRC and other parameters including, clay, silt and sand percent and bulk density using regression analysis were established as follows:

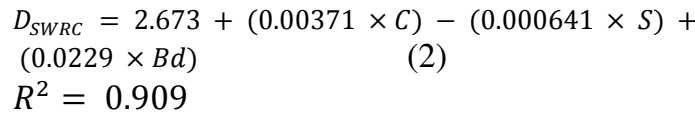

$R^{2}=0.909$

in which, $\mathrm{D}_{\text {SWRC }}$ is the estimated fractal dimension of soil water retention curve, $\mathrm{C}$ and $\mathrm{S}$ are clay and silt content and $\mathrm{Bd}$ is soil bulk density $\left(\mathrm{cm}^{3} \mathrm{~cm}^{-3}\right)$.

The regression analysis showed a high correlation between $\mathrm{D}_{\text {SWRC, }}$ clay and silt content and soil bulk density with goodness of fit, $\mathrm{R}^{2}=0.909$. Also The values of maximum, minimum and average soil moisture curve measured fractal dimensions for texture studied.

Estimated fractal dimension values depended on soil texture as soils with coarse texture had lower fractal dimension values than soils with fine texture. Tyler and Wheatcraft (1992), Rieu and Sposito (1991b) as well as Filgueira et al., (1999) and Kravchenko and Zhang (1998) using respectively, the soil mass distribution, the aggregate size distribution and the particle-size distribution in the three-dimensional Euclidian domain, have found that the fractal dimension of soils were in the range of 2 to 3 .
$\mathrm{D}_{\text {SWRC }}$ could be approximated by using clay and silt contents and soil bulk density as obtained regression model.

A comparison of estimated fractal dimension values with obtained regression model and measured fractal dimension with soil moisture curve is shown in Fig. 1. Table 3 shows the MAE, MSE and $\mathrm{R}^{2}$ obtained from comparing all data of the measured soil water content versus the estimated by using obtained regression model. The results showed a reasonably good estimation of soil water retention curves for the most of soils. Similar results were also found by Fazeli et al., (2010).
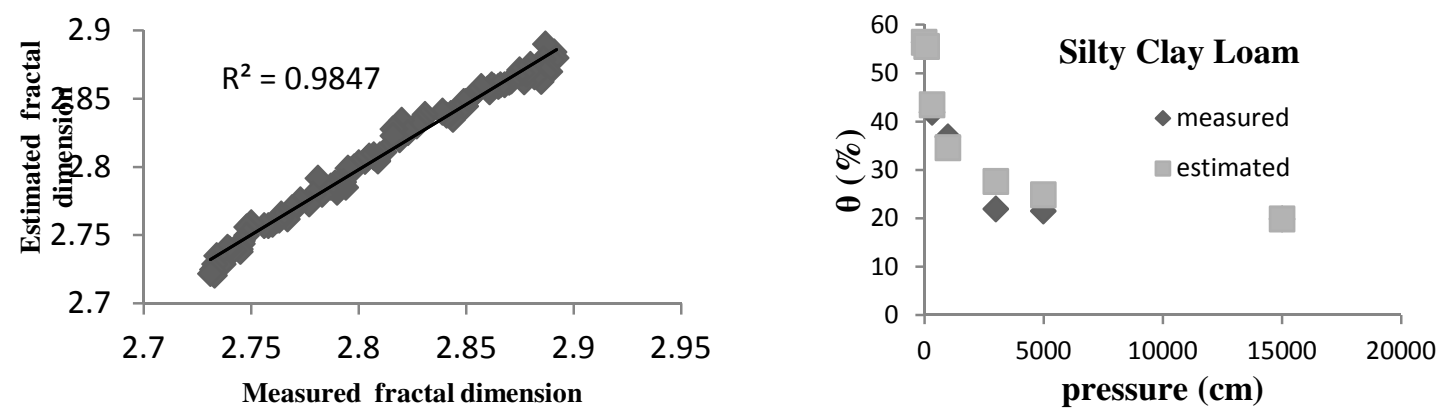

Fig 1: Distribution of estimated fractal dimension values with obtained regression model and measured fractal dimension with soil moisture curve 
Table 3: MAE, MSE and $\mathrm{R}^{2}$ obtained from comparing all data of the measured soil water content versus estimated by using obtained

\begin{tabular}{cccc}
\multicolumn{4}{c}{ regression model. } \\
\hline & MAE & MSE & $\mathbf{R}^{2}$ \\
\hline Fractal & 0.0072 & $7.699 \mathrm{E}-05$ & 0.9658 \\
\hline
\end{tabular}

Estimated and measured SWRC had shown in figure 2 for five typical soil: Silty Loam, Clay Loam, Silty Clay Loam, Silty Clay and Clay. Results showed that for most of the soils, using regression relationship, gave a good estimation of SWRC. Additionally, linear regression of the measured and estimated SWRC for validation data set showed that the intercept values for all tested soils were close to zero, most of the slope values were close to unity, and the coefficients of determination (r2) between the estimated results and measured data for all soils ranged from 0.993 to 0.998 . Hence, this method (clay and silt contents and bulk density), could be recommended for estimating SWRC.
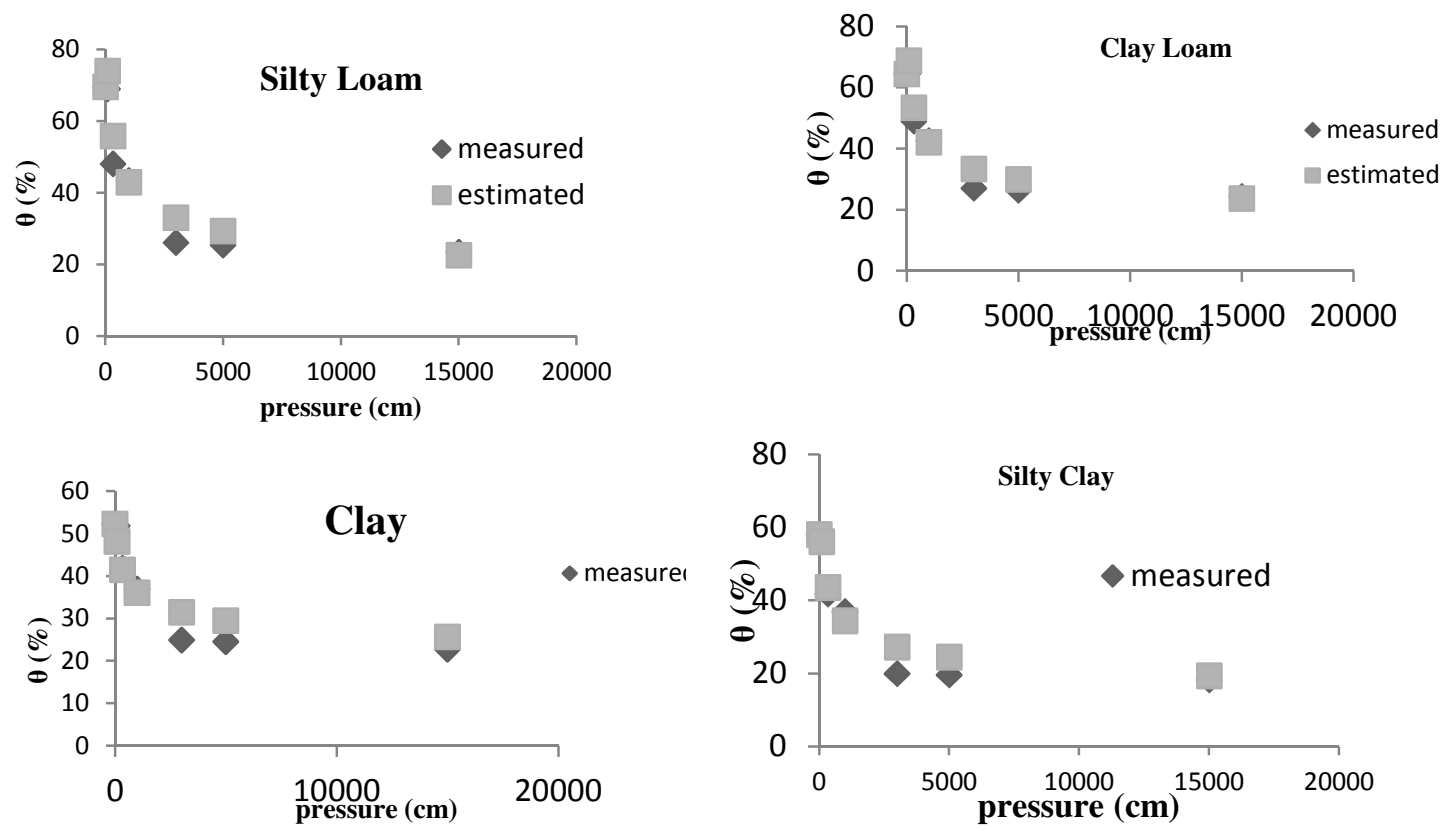

Fig 2: Estimated and measured SWRC for five typical soils: Silty Loam, Clay Loam,

Silty Clay Loam, Silty Clay and Clay.

Conclusion: In this study the SWRC were predicted using fractal dimensions of SWRC ( $\left.D_{\text {SWRC }}\right)$ and relationship between $D_{\text {SWRC }}$ and soil readily available characteristics were analyzed. Regression analysis showed a linear relationship between $\mathrm{D}_{\text {SWRC }}$, clay and silt content and soil bulk density. The results indicated that obtained regression model was capable in predicting $\mathrm{D}_{\mathrm{SWRC}}$ of Tyler and Wheatcraft model with reasonable accuracy. So, this method can be used with acceptable accuracy in estimating soil retention curve based on easily available soil data.

\section{REFERENCES}

Blake, GR; Hartge, KH (1986). Bulk density. In: Klute, A.,

(Ed.), Methods of Soil Analysis. Part1- Physical and Mineralogical Methods. Seconds edition. Agronomy No.9, America Society of Agronomy, Inc. Soil Science Society of America, Madison, Wisconsin, USA.

Borodich, FM (1997). Some Fractal Models of Fracture. J. Mech. Phys. Solids. 45: 239-259
Brooks, RH; Corey, AT (1964). Hydrolic Properties of Porous Media. Hydrology Paper No. 3, Colorado State Univ. Fort Collins, CO.

Brooks, RH; Corey, AT (1966). Properties of Porous Media Affecting Fluid Flow. ASCE. J. Irrig. Drain. Div. 92: 61-68.

Burdine, NT (1953). Relative Permeability Calculations from Pore-Size Distribution Data. Trans. Am. Inst. Min. Engrs. 198: 71-79.

Cihan, A; Perfect, E; Tyner, JS (2007). Water Retention Models For Scale-Variant and Scale-Invariant Drainage of Mass Prefractal Porous Media. Vadose Zone J. 6: 786-792.

Comegna, V; Damiani, P; Sommella, A (2000). Scaling the Saturated Hydraulic Conductivity of a Vertic Ustorthens Soil under Conventional and Minimum Tillage. Soil Till. Res. 54: 1-9.

Elsenbeer, H (2001). Pedotransfer Functions in Hydrology. J. Hydrol. 251: 121-122.

Fazeli, M; Shorafa, M; Namdar Khojasteh, D; Pilevar Shahri, AR (2010). A Fractal Approach for Estimating 
Soil Water Retention Curve. Journal of Soil Science and Environmental Management. 1(7): 177-183.

Filgueira, RR; Pachepsky, YA; Fournier, LL; Sarli, GO; Aragon, A (1999). Comparison of Fractal Dimensions Estimated from Aggregate Masssize Distribution and Water Retention Scaling. Sod. Sci. 164: 217-223.

Ghanbarian-Alavigeh, B; Liaghat, AM; Shorafa, M; Moghimi-Araghi, S (2007). Evaluation of Perefect Fractal Model in Estimation of Soil Water Retention Curve. Iranian J. Irrig. Drain. 1: 7-19.

Ghanbarian, B; Liaghat, AM; Huang, GH (2008). Prediction of Soil Water Retention Curve: A Sensitivity Analysis and Calibration of SWRC Fractal Model. EGU General Assembly, Ienna, Austria.

Ghanbarian-Alavijeh, B; Hunt, AG (2012). Estimation of Soil-Water Retention from Particle-Size Distribution: Fractal Approaches. Soil Sci. 177: 321-326.

Gime'nez, D; Perfect, E; Rawls, WJ; Pachepsky, Y (1997). Fractal Models for Predicting Soil Hydraulic Properties: A Review Eng. Geol. 48: 161-183.

Hillel, D (1998). Environmental Soil Physics. Academic Press, Inc. New York, p.771.

Huang, G.H; Zhan, WH (2002). Fractal Property of Soil Particle Size Distribution and Its Application. Acta Pedologica Sinica. 39: 490-497.

Huang, G; Zhang, R (2005). Evaluation of Soil Water Retention Curve with the Pore-Solid Fractal Model. Geoderma. 127: 52-61.

Kravchenko, A; Zhang RD (1998). Estimating the Soil Water Retention from Particle-Size Distributions: A Fractal Approach. Soil Sci. 163: 171-179.

Minasny, B; McBratney, AB; Bristow, KL (1999). Comparison of Different Approaches to the Development of Pedotransfer Functions for WaterRetention Curves. Geoderma. 93: 225-253.

Moravvej, K; Sarmadian, F; Mahmoodi, Sh (2003). Classification and Mapping of Varamin Plain Soils Using Satellite Images Derived from T.M. Sensors. Iranian J. Natural Res. 56(3): 177-189.

Mualem, Y (1976). A New Model for Predicting the Hydraulic Conductivity of Unsaturated Porous Media. Water Resour. Res. 12(3): 513-522.

Patil, SB; Chore, HS (2014). Contaminant Transport through Porous Media: An Overview of Experimental and Numerical Studies. Advances in Environmental Research. 3(1): 45-69.

Perfect, E; McLaughlin, NB; Kay, BD; Topp, GC (1998). Reply to the Comment on "An Improved Fractal Equation for the Soil Water Retention Curve". Water Resour. Res. 34: 933-935.

Perfect, E (2005). Modeling the Primary Drainage Curve of Prefractal Porous Media. Vadose Zone J. 4: 959-966.

Perrier, E; Rieu, M; Sposito, G; de Marsily, G (1996). Models of Water Retention Curve for Soils with Fractal Pore Size Distribution. Water Resour. Res. 32: 3025-3031.
Rieu, M; Sposito, G (1991a). Fractal Fragmentation, Soil Porosity and Soil Water Properties: I. Theory. Soil Sci. Soc. Am. J. 55: 1231-1238.

Rieu, M; Sposito, G (1991b). Fractal Fragmentation, Soil Porosity and Soil Water Properties: 11. Appl. Soil Sci. SOCA. Am. J. 55: 1239-1244.

Russo, D (1988). Determining Soil Hydraulic Properties by Parameter Estimation: On The Selection of a Model for the Hydraulic Properties. Water Resour. Res. 110: 453-459.

Schaap, MG; Leij, FL; van Genuchten, MTh (1998). Neural Network Analysis for Hierarchical Prediction of Soil Hydraulic Properties. Soil Sci. Soc. Am. J. 62: 847855.

Scheinost, AC; Sinowsi, W; Auerswald, K (1997). Reginalization of Soil Water Retention Curves in Highly Variable Soil Scope: I. Developing a New Pedotransfer Function. Geoderma. 78: 29-143.

Toledo, PG; Novy, RA; Davis, HT; Scriven, LE (1990). Hydraulic Conductivity of Porous Media at Low Water Content. Soil Sci. Soc. Am. J. 54: 673-679

Turcotte, DL (1992). Fractals and Chaos in Geology and Geophysics Cambridge Univ. Press, Cambridge.

Tyler, SW; Wheatcraft, SW (1990). Fractal Process in Soil Water Retention. Water Resour. Res. 26: 1047-1054.

Tyler, SW; Wheatcraft, SW (1992). Fractal Scaling of Soil Particle-Size Distributions: Analysis and Limitations. Soil Sci. Soc. Am. J. 56: 362-369.

Van Damme, H (1995). Scale Invariance and Hydric Behaviour of Soils and Clays. CR. Acad. Sci. Paris. 320: 665-81.

Van Genuchten, MTh (1980). A Close Form Equation for Predicting the Hydraulic Conductivity of Unsaturated Soils. Soil Sci. Soc. Am. J. 44: 892-897.

Wang, Z; Zhou, YC; Yu, N (2005). Feasibility Research on Estimating the Soil Water Retention Curve of Brown Earth with Fractal Method. J. Shenyang Agric. Univ. 36: $570-574$

Wosten, JHM; Pachepsky, YA; Rawls, WJ (2001). Pedotransfer Function: Bridging the Gap between Available Basic Soil Data and Missing Soil Hydraulic Characteristics. J. Hydrol. 251: 123-150.

Xu, YF; Sun, DA (2002). A Fractal Model for Soil Pores and Its Application to Determination of Water Permeability. Physica A. 316 (1-4): 56-64. 